\title{
Electrochemical Characterization of a Novel Salen-Type Modified Electrode
}

\author{
M. Vilas-Boas, ${ }^{\dagger}$ C. Freire $, *, \dagger$ B. de Castro,${ }^{\dagger}$ and A. R. Hillman ${ }^{\dagger}$ \\ CEQUP/Departamento de Química, Faculdade de Ciências, Universidade do Porto, 4150 Porto, Portugal, and \\ Department of Chemistry, University of Leicester, Leicester LE1 7RH, United Kingdom
}

Received: May 7, 1998; In Final Form: July 31, 1998

\begin{abstract}
The nickel(II) complex with $\mathrm{H}_{2}$ saltMe, a $\mathrm{N}_{2} \mathrm{O}_{2}$ Schiff base ligand derived from salicylaldehyde, was oxidatively electropolymerized on $\mathrm{Pt}$ electrodes in $\mathrm{CH}_{3} \mathrm{CN} / 0.1 \mathrm{~mol} \mathrm{dm}{ }^{-3}$ tetraethylammonium perchlorate (TEAP) to generate polymer films that exhibit reversible oxidative electrochemical behavior in a wide potential range $(0.0-1.3 \mathrm{~V})$, high conductivity, and stability/durability. The films of poly[Ni(saltMe)] can be made to exhibit the three regimes of charge transport behavior by manipulation of the film thickness and the experimental time scale. Films prepared by a small number of potential cycles show thin-layer/surface-type cyclic voltammetry behavior in the scan rate range used. Thicker polymers exhibit a changeover from this thinlayer regime to diffusion control at a critical scan rate that depends on film thickness. In chronoamperometry experiments a transition from semiinfinite diffusion to finite diffusion conditions was observed at longer times following the potential step.Values of $D^{1 / 2} \mathrm{C}$ for the second electrochemical stage of film oxidation redox obtained from both techniques were in good agreement. A comparison of the values for oxidative and reductive electrochemical reactions suggests that ingress of counterions and solvent swelling must occur predominantly up to $0.8 \mathrm{~V}$ in the positive going potential scan.
\end{abstract}

\section{Introduction}

Solution redox chemistry of nickel(II) complexes with $\mathrm{N}_{2} \mathrm{O}_{2}$ Schiff base ligands is a theme of current interest due to their use as homogeneous electrocatalysts. ${ }^{1-3}$ More recently, the ease of preparation of metal salen-based modified electrodes by oxidative electropolymerization of the monomers in weak donor solvents ${ }^{4-11}$ has prompted their use in heterogeneous electrocatalysis. ${ }^{12}$ In this connection, knowledge of the structure and electrochemical responses/charge storage mechanisms and of the associated kinetics of these transition metal-based polymers will play a critical role in their practical application to electrocatalytic reactions.

Oxidation/reduction of electroactive species deposited at electrode surfaces promotes the ingress of counterions from the electrolyte solution to maintain electroneutrality and movement of co-ions and solvent molecules associated with the flux of counterions into the film. Thus, it is possible that either electron or ion transport may constitute the rate-limiting step of the overall charge transport process in polymer-modified electrodes.

A modified electrode with a film of uniform composition and thickness, which exhibits diffusive charge transport, may do so at rates that (when compared with the time scale associated with the experimental electrochemical technique) may be classified as fast, slow, or intermediate. If charge transport is faster than the experimental time scale, the concentration of oxidized/ reduced sites within the film will be uniform and in thermodynamic equilibrium with the applied electrode potential, and the current-potential curves will have a symmetrical shape. For slow charge transport, a diffusional-type response is observed

* Address correspondence to this author at the Departamento de Química, Faculdade de Ciências, Universidade do Porto, Rua do Campo Alegre, 687, 4150 Porto, Portugal. E-mail acfreire@fc.up.pt; tel ++/351/2/6082890; Fax: $++/ 351 / 2 / 6082959$.

$\dagger$ Universidade do Porto.

$\doteqdot$ University of Leicester. for which the rate-limiting step is the flux of species from the "bulk" to the electrode surface. In this case the oxidation and reduction current responses are asymmetric and obey the Randles-Sevcik equation, and chronoamperometric responses will obey the Cottrell equation. ${ }^{13}$ At intermediate charge transport rates, the concentration profiles are confined by the outer boundary of the polymer film, and the polymer is considered as a finite volume of reactant. ${ }^{13}$

The preparation of modified electrodes by oxidative electropolymerization of nickel(II) complexes with $\mathrm{N}_{2} \mathrm{O}_{2}$ Schiff base ligands derived from salicylaldehyde has been performed by several groups. ${ }^{4-11}$ These studies have considered the electropolymerization process, polymer structure, identification of the surface redox couples, and the mechanism of electron transport. ${ }^{4-11}$ In our previous work on the electrochemical and spectroscopic characterization of poly[Ni(salen) $]^{11}$ no data on the kinetics of the charge transport could be obtained, mainly due to stability/durability limitations of the surface electrogenerated polymer. These stability problems are present in the majority of these salen-type polymers and therefore, to our knowledge, no data on the kinetics of charge transport in these polymers have been published.

We are pursuing our studies in the redox chemistry of nickel(II) complexes with Schiff base ligands in order to increase the stability/durability of their related polymers. We have been preparing new ligands by using salen-type derivatives for which different substituents have been introduced in the ethylenimine bridge. By substitution of the four hydrogens by four methyl groups in the ethylene bridge of $\mathrm{H}_{2}$ salen, the monomer [Ni(saltMe)] (Chart 1) was prepared, and its redox chemistry has been studied in several solvents; ${ }^{14}$ the work reported herein relates its electrochemical behavior in $\mathrm{CH}_{3} \mathrm{CN}$.

As was observed for similar $\mathrm{Ni}(\mathrm{II})$ complexes, oxidative electropolymerization of [ $\mathrm{Ni}($ saltMe $)]$ occurs in this solvent and a novel surface-modified electrode with very high conductivity 


\section{CHART 1}

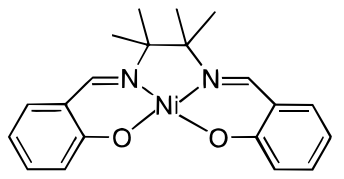

and stability/durability was obtained. These properties allowed, for the first time, the study of the dynamics of charge transport across the film and its dependence on film thickness for a nickel salen-type modified electrode. We determined charge transport parameters as a function of time scale, using both chronoamperometry (a short time scale potential-step method) and cyclic voltammetry (a longer time scale method), and the results showed that poly[Ni(saltMe)] can be made to exhibit the three regimes of charge transport behavior by manipulation of the film thickness and the experimental time scale. Morphological characterization of the film was provided by scanning electron microscopy.

\section{Experimental Section}

Materials. The complex 2,3-dimethyl- $N, N^{\prime}$-bis(salicylidene)butane-2,3-diaminatonickel(II) [Ni(saltMe)], was prepared by a procedure described in the literature ${ }^{14}$ and recrystallized from acetonitrile. Tetraethylammonium perchlorate, TEAP (Fluka, puriss), was used as received and dried in an oven at $60{ }^{\circ} \mathrm{C} \mathrm{p}$ to use. Acetonitrile (Fisons, HPLC grade) was refluxed twice over $\mathrm{CaH}_{2}$ and distilled under argon before use.

Instrumentation: (a) Electrochemistry. Electrochemical measurements were performed with an Autolab PGSTAT20 potentiostat/galvanostat. The electrochemical cell was a closed standard three-electrode cell that was connected to a solution reservoir through a Teflon tube. A Pt disk electrode with an area of $0.0314 \mathrm{~cm}^{2}$ was used as working electrode and a $\mathrm{Pt}$ gauze electrode as the counterelectrode. All potentials refer to an $\mathrm{Ag} / \mathrm{AgCl}\left(1 \mathrm{~mol} \mathrm{dm}^{-3} \mathrm{NaCl}\right)$ reference electrode. Prior to use, the Pt working electrode was polished with an aqueous suspension of $0.05 \mu \mathrm{m}$ alumina (Beuhler) on a Master-Tex (Beuhler) polishing pad, then rinsed with water and acetone and dried in the oven. All solutions were deareated and delivered to the cell by a stream of Ar.

(b) Scanning Electron Microscopy. A scanning electron microscope (Jeol J5M 35C) coupled with an X-ray detector (Noram Instruments) and an analyzer (Noram Voyager) was used to provide information on morphological characterization and composition of the polymer films deposited on a Pt foil with an area of $3.25 \mathrm{~cm}^{2}$.

Procedures. Poly[Ni(saltMe)] films were deposited by cycling the potential of the working electrode between 0.0 and $1.3 \mathrm{~V}$ at $0.1 \mathrm{~V} \mathrm{~s}^{-1}$, immersed in a $\mathrm{CH}_{3} \mathrm{CN}$ solution containing $1 \mathrm{mmol} \mathrm{dm}^{-3}$ [Ni(saltMe)] monomer and $0.1 \mathrm{~mol} \mathrm{dm}^{-3}$ TEAP. Films of different thickness were prepared by using different numbers of potential cycles; a coulometric assay in monomerfree solution for each film yielded the respective polymer electroactive surface coverage, $\Gamma$ (moles per square centimeter), with the assumption that one positive charge is delocalized over each monomer unit (see below). The voltammograms used in the calculation of the electroactive surface coverage were performed at $0.01 \mathrm{~V} \mathrm{~s}^{-1}$, to ensure that the oxidation/reduction processes occur throughout the whole film.

After electropolymerization, the modified electrode was thoroughly rinsed with dry $\mathrm{CH}_{3} \mathrm{CN}$ and all the electrochemical characterization experiments were carried out on films immersed in $0.1 \mathrm{~mol} \mathrm{dm}{ }^{-3} \mathrm{TEAP} / \mathrm{CH}_{3} \mathrm{CN}$. For cyclic voltammetric

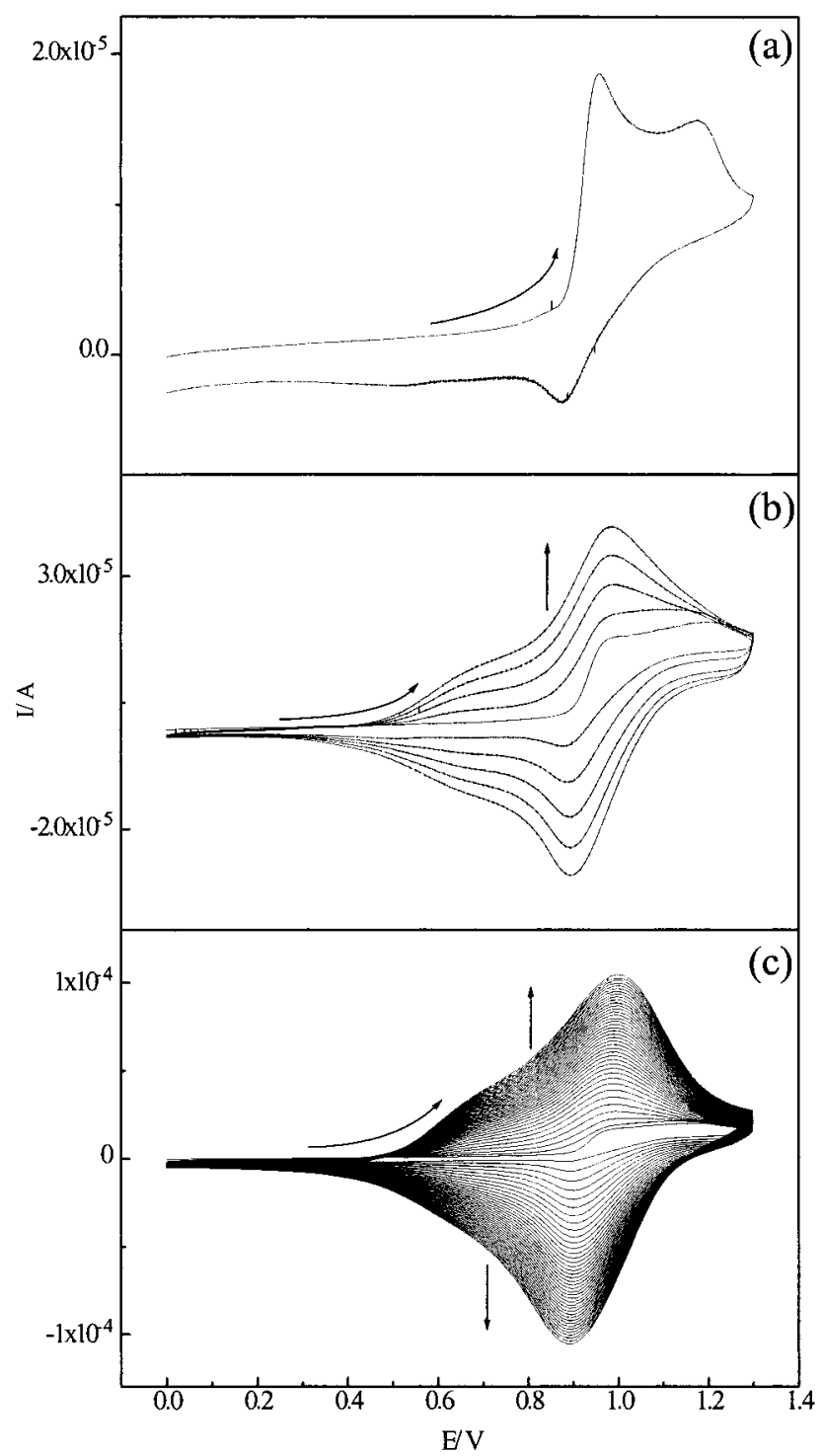

Figure 1. Cyclic voltammogram showing the anodic polymerization of $1 \mathrm{mmol} \mathrm{dm}-3$ [Ni(saltMe)] in $0.1 \mathrm{~mol} \mathrm{dm}{ }^{-3} \mathrm{TEAP} / \mathrm{CH}_{3} \mathrm{CN}$ at a platinum disk electrode, between 0.0 and $1.3 \mathrm{~V}$ at $0.100 \mathrm{~V} \mathrm{~s}^{-1}$; (a) one scan; (b) five scans; (c) 50 scans.

experiments the film was cycled between 0.0 and $1.3 \mathrm{~V}$ at scan rates in the range $0.005-2.0 \mathrm{~V} \mathrm{~s}^{-1}$; for chronoamperometric experiments the polymer was first scanned at $0.1 \mathrm{~V} \mathrm{~s}^{-1}$ until a reversible voltammogram was observed, and then three different potential steps were applied: (i) from 0.0 to $0.8 \mathrm{~V}$ and returning to $0.0 \mathrm{~V}$; (ii) from 0.0 to $1.1 \mathrm{~V}$ and returning to $0.0 \mathrm{~V}$, and finally (iii) from 0.0 to $0.8 \mathrm{~V}$, then from 0.8 to $1.1 \mathrm{~V}$ and returning to $0.8 \mathrm{~V}$, and then to $0.0 \mathrm{~V}$. Chronoamperometric experiments were performed on polymer films prepared by 5-50 polymerization voltammetric cycles, corresponding to $\Gamma$ in the range $0.96 \times 10^{-8}$ to $11.0 \times 10^{-8} \mathrm{~mol} \mathrm{~cm}^{-2}$.

The Pt-modified electrode used in SEM experiments was prepared by immersing the bare electrode in a $0.1 \mathrm{~mol} \mathrm{dm}^{-3}$ TEAP/ $\mathrm{CH}_{3} \mathrm{CN}$ solution containing $1.0 \mathrm{mmol} \mathrm{dm}{ }^{-3}$ [Ni(saltMe)] and holding the potential at $1.3 \mathrm{~V}$ for $600 \mathrm{~s}$. After film deposition, two different procedures were used, depending on the desired oxidation state: (i) for oxidized polymers, the modified electrode was rinsed with dry $\mathrm{CH}_{3} \mathrm{CN}$ and dried under Ar; (ii) for neutral polymers, the modified electrode was rinsed with dry $\mathrm{CH}_{3} \mathrm{CN}$, cycled in a monomer-free solution between 0.0 and $1.3 \mathrm{~V}$ at $0.1 \mathrm{~V} \mathrm{~s}^{-1}$, and dried under Ar. 


\section{Results and Discussion}

Electrochemical Polymerization. Cyclic voltammetry of the monomer in the strong donor solvents $\left(\mathrm{CH}_{3}\right)_{2} \mathrm{SO}$ and dimethylformamide (DMF) has been published, ${ }^{14}$ in both solvents the complex [ $\mathrm{Ni}($ saltMe)] is oxidized to $\mathrm{Ni}(\mathrm{III})$ in a quasi-reversible diffusion-controlled one-electron transfer process, with redox couples at $E_{1 / 2}=0.87 \mathrm{~V}$ in $\left(\mathrm{CH}_{3}\right)_{2} \mathrm{SO}$ and $E_{1 / 2}=0.94 \mathrm{~V}$ in DMF. The electrochemical behavior of [Ni(saltMe)] in $\mathrm{CH}_{3}-$ $\mathrm{CN}$ is different from that observed in strong donor solvents, as has been observed for other $\mathrm{Ni}(\mathrm{II})$ complexes with similar ligands. ${ }^{4-11}$

Figure 1a depicts the cyclic voltammogram of [Ni(saltMe)] in $\mathrm{CH}_{3} \mathrm{CN}$ at a bare $\mathrm{Pt}$ electrode. As the potential is scanned to $1.3 \mathrm{~V}$, two overlapping anodic waves are observed at ca. 0.96 and $1.17 \mathrm{~V}$, and on the reverse scan, one cathodic wave at ca. $0.87 \mathrm{~V}$ and a shoulder around $0.69 \mathrm{~V}$ were detected. Qualitative inspection of the anodic and cathodic charge passed in the first potential cycle clearly indicates an irreversible process.

In the second potential scan, Figure $1 b$, a new anodic wave appears at $0.74 \mathrm{~V}$ and an increase in peak current of the other waves was observed, except that at $E_{\mathrm{pa}}=1.17 \mathrm{~V}$ which remains constant. In subsequent scans there is a continuous increase in peak current, Figure $1 \mathrm{c}$, except for that with $E_{\mathrm{pa}}=1.17 \mathrm{~V}$, which becomes practically nonobservable after the third scan.

Visual inspection of the electrode surface shows deposition of a yellow-green film; as this film is not dissolved upon subsequent anodic or cathodic sweeps, it cannot be due to precipitation of an insoluble monomeric [Ni(saltMe)]-based complex. In accordance with our previous work on the oxidative chemistry of $\left[\mathrm{Ni}(\right.$ salen) $]$ in $\mathrm{CH}_{3} \mathrm{CN},{ }^{11}$ and with the work of Goldsby, ${ }^{4,5}$ Audebert, ${ }^{6-8}$ Bedioui, ${ }^{9}$ and Dahm ${ }^{10}$ on the oxidative chemistry of metal complexes with $\mathrm{N}_{2} \mathrm{O}_{2}$ Schiff base ligands derived from salicylaldehyde, we conclude that the product of the oxidation of $[\mathrm{Ni}($ saltMe $)]$ is also a polymeric material.

In the context of the above statement, the new anodic wave at $0.74 \mathrm{~V}$ is attributed to the film and must correspond to the anodic counterpart of the cathodic process detected at $0.69 \mathrm{~V}$. Furthermore, the continuous increase in peak current during cycling (Figure 1b,c), even for the longest potential cycling experiments performed (160 cycles), is due both to an increase of the surface coverage as a result of the film deposition and to oxidation of the polymer formed on previous potential scans.

To decide whether the electroactivity was due to the monomer or to the film, the modified electrode was immersed in a monomer-free solution, to ensure the current to be solely attributable to the surface-bound structure. Figure 2a depicts the typical electrochemical responses attributable to the oxidative redox switching of one film prepared by one potential scan polymerization. In the first scan we can observe two anodic waves, at potential values that are very similar to those of the polymerization, $c a$. 0.65 and $0.92 \mathrm{~V}$, as well as a shoulder around $1.14 \mathrm{~V}$ and two cathodic waves at 0.64 and $0.89 \mathrm{~V}$. However, after the second scan, the anodic shoulder at $1.14 \mathrm{~V}$ disappears and a reversible electrochemical system with two redox couples at $E_{1 / 2}(\mathrm{I})=0.65 \mathrm{~V}$ and $E_{1 / 2}(\mathrm{II})=0.91 \mathrm{~V}$ is observed.

The difference between the voltammograms for the first and subsequent scans has been also reported in studies of the oxidative electropolymerization of other $\mathrm{Ni}$ (II) complexes with $\mathrm{N}_{2} \mathrm{O}_{2}$ Schiff base ligands. Hoferkamp and Goldsby in their study of poly[Ni(salen) $]^{4}$ have attributed this difference to oxidation of traces of residual monomer and of unpolymerized

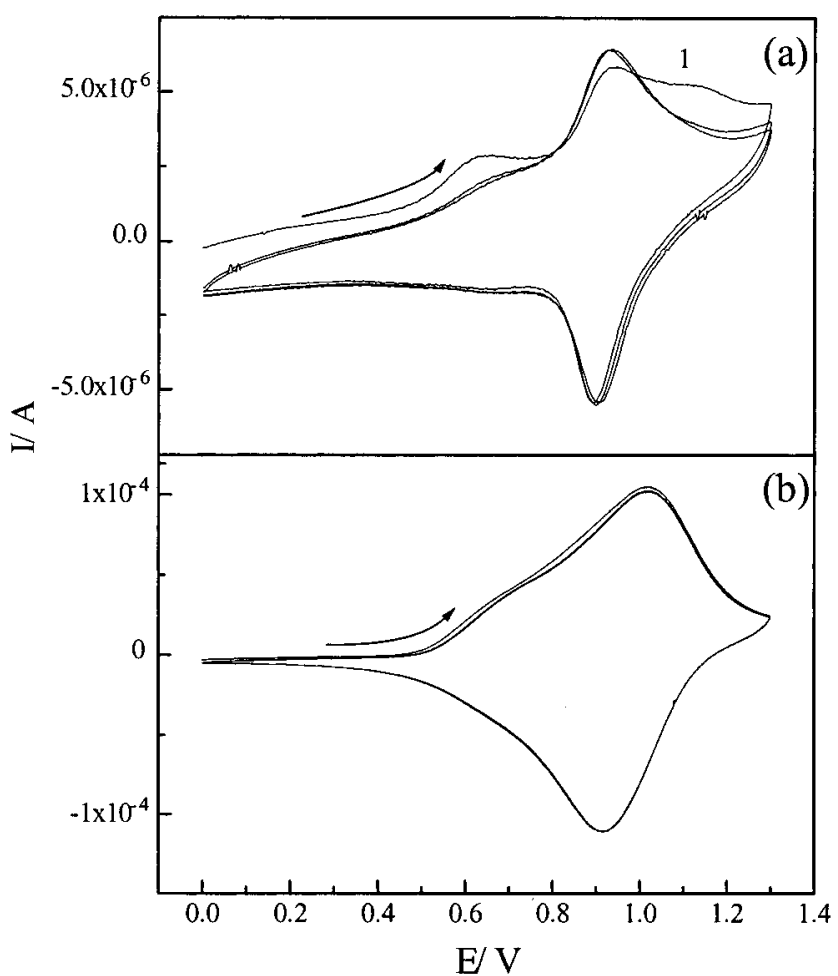

Figure 2. Cyclic voltammogram of a poly[Ni(saltMe)]-modified electrode in $0.1 \mathrm{~mol} \mathrm{dm}^{-3} \mathrm{TEAP} / \mathrm{CH}_{3} \mathrm{CN}$ between 0.0 and $1.3 \mathrm{~V}$ at $0.100 \mathrm{~V} \mathrm{~s}^{-1}$, obtained with (a) one polymerization scan or (b) 50 polymerization scans.

oligomers trapped within the polymer matrix, whereas Dahm et al. ${ }^{10}$ have associated it with electrochemical modifications of the fresh polymer formed with only one scan.

Excluding the first scan of redox switching for thin films, all polymers exhibit reproducible and reversible voltammograms after being cycled for several days in $0.1 \mathrm{~mol} \mathrm{dm}^{-3}$ TEAP/ $\mathrm{CH}_{3} \mathrm{CN}$.

Coulometric Studies. We now consider the coulometry of the system, for a single scan polymerization and subsequent redox switching of the film, to determine the degree of oxidation for each monomer unit.

In our previous work on poly[Ni(salen)] we proposed that three processes contribute to the overall charge passed: polymerization, ligand-based redox processes, and metal-based redox processes. ${ }^{11}$ The number of electrons per monomer unit associated with each process was proposed to be: 2 electrons (and two protons) for polymerization, $z$ electrons for the metalbased redox switching ( $z=0$ or 1 ), and $2 y$ electrons for the ligand-based redox switching ( $y$ electrons per phenyl ring). The ratio of the anodic charge passed in the polymerization/ deposition to that in redox switching is given by $Q_{\mathrm{pol}} / Q_{\text {redox }}=$ $(2+2 y+z) /(2 y+z)$. Using the same approach for poly[Ni(saltMe)], we find this ratio to be $3.05 \pm 0.26$, and the only solution with physical significance requires $z=0$ and $y=0.48$ \pm 0.03 . On the basis of these results, and for the positive potential limit employed, we found that in poly[Ni(saltMe)] approximately one positive charge is delocalized through one monomer unit.

However, to achieve a clear-cut distinction between a ligandbased and a metal-based oxidative behavior for poly[Ni(saltMe)], electrochemical data must be complemented by spectroscopic data [in situ UV-vis and Fourier transform infrared (FTIR) and ex-situ electron paramagnetic resonance (EPR)]. Our spectroscopic results, to be published elsewhere, 


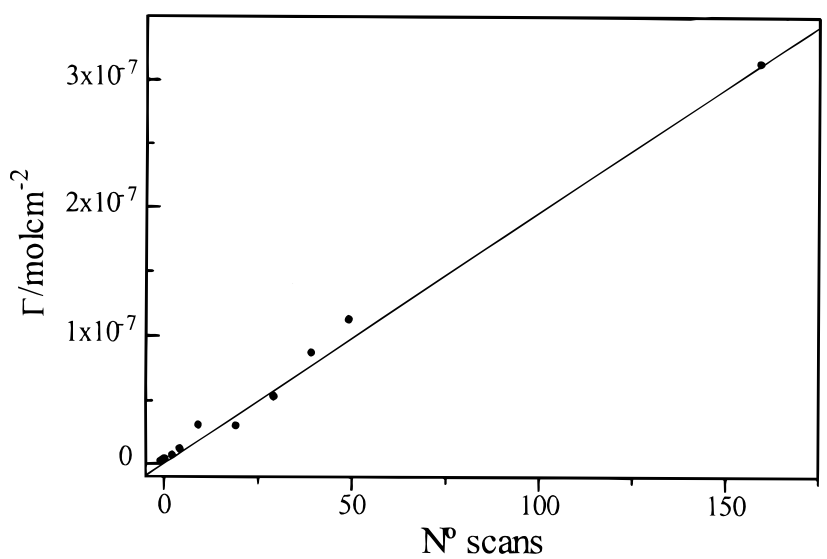

Figure 3. Plot of the apparent surface coverage, $\Gamma$, with the number of scans employed in the polymerization. All the modified electrodes were prepared as in Figure 2.

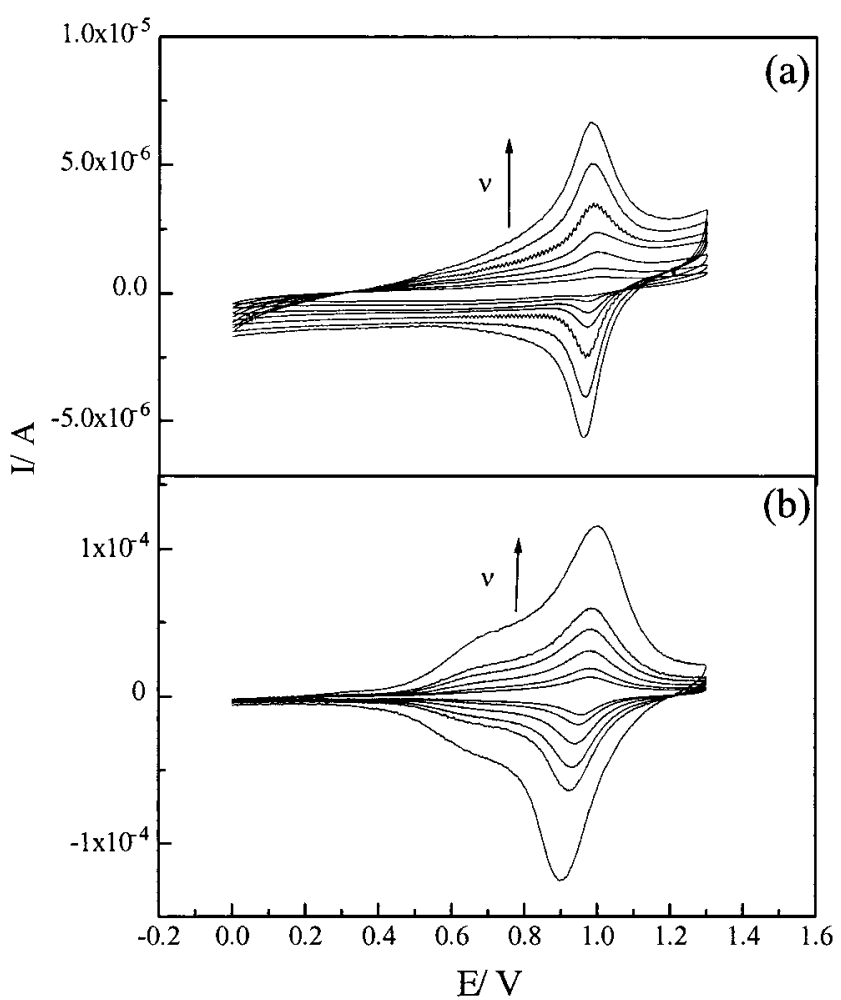

Figure 4. Cyclic voltammograms for a poly[Ni(saltMe)]-modified electrode in $0.1 \mathrm{~mol} \mathrm{dm}{ }^{-3} \mathrm{TEAP} / \mathrm{CH}_{3} \mathrm{CN}$ between 0.0 and $1.3 \mathrm{~V}$, obtained with five polymerization scans $\left(\Gamma=9.6 \times 10^{-9} \mathrm{~mol} \mathrm{~cm}^{-2}\right)$ at different scan rates: (a) $0.005,0.01,0.02,0.03,0.05,0.075$, and 0.1 $\mathrm{Vs}^{-1}$; (b) $0.2,0.3,0.5,0.75,1$, and $2 \mathrm{~V} \mathrm{~s}^{-1}$.

show that polymerization and oxidative redox switching of poly$[\mathrm{Ni}(\mathrm{saltMe})]$ are ligand-based processes, as observed for poly$[\mathrm{Ni}($ salen $)] .^{11}$

Effect of Coverage. Good film conductivity (when exposed to solution) was demonstrated from the dependence of the electroactive surface coverage, $\Gamma$, on the number of polymerization scans. Values of $\Gamma$ were plotted as a function of the number of electropolymerization cycles (Figure 3 ). $\Gamma$ was found to increase linearly, indicating that, even for very thick films, poly[Ni(saltMe)] behaves as a conducting polymer. This behavior is to be contrasted with that observed for related polyNi(II) complexes and other metal complex-based polymers ${ }^{15-17}$ for which poor film conductivity is observed for thick films. The importance of the high conductivity we observe here is that all nickel sites are electrochemically accessible.

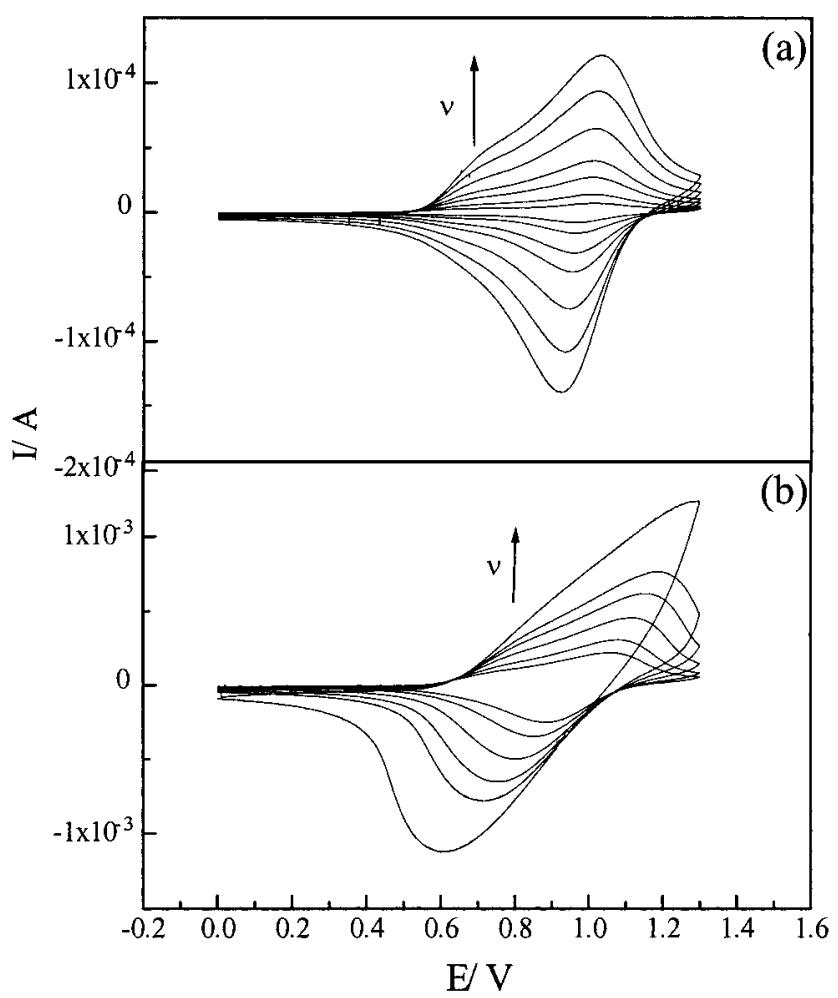

Figure 5. Cyclic voltammograms for a poly[Ni(saltMe)]-modified electrode in $0.1 \mathrm{~mol} \mathrm{dm}^{-3} \mathrm{TEAP} / \mathrm{CH}_{3} \mathrm{CN}$ between 0.0 and $1.3 \mathrm{~V}$, obtained with 50 polymerization scans $\left(\Gamma=1.1 \times 10^{-7} \mathrm{~mol} \mathrm{~cm}^{-2}\right)$ at different scan rates: (a) $0.005,0.01,0.02,0.03,0.05,0.075$, and $0.1 \mathrm{~V}$ $\mathrm{s}^{-1}$; (b) $0.2,0.3,0.5,0.75,1$, and $2 \mathrm{~V} \mathrm{~s}^{-1}$.

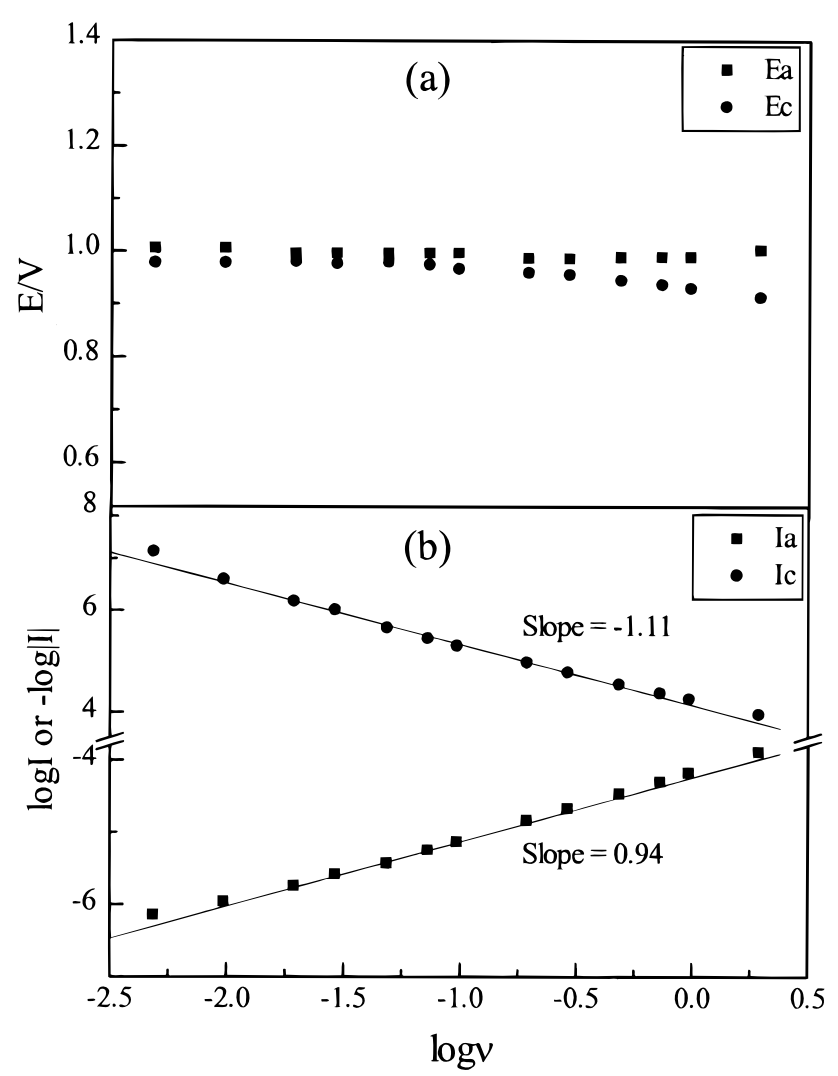

Figure 6. Dynamic studies of the poly[Ni(saltMe)]-modified electrode of Figure 4, $\Gamma=9.6 \times 10^{-9} \mathrm{~mol} \mathrm{~cm}^{-2}$ : (a) plot of $E_{\mathrm{a}}$ and $E_{\mathrm{c}} \mathrm{vs} \log v$; (b) plot of $\log I_{\mathrm{a}}$ and $I_{\mathrm{c}}$ vs $\log v$.

Cyclic Voltammetric Studies. Figures 4 and 5 show, respectively, the voltammetric responses of poly[Ni(saltMe)] 


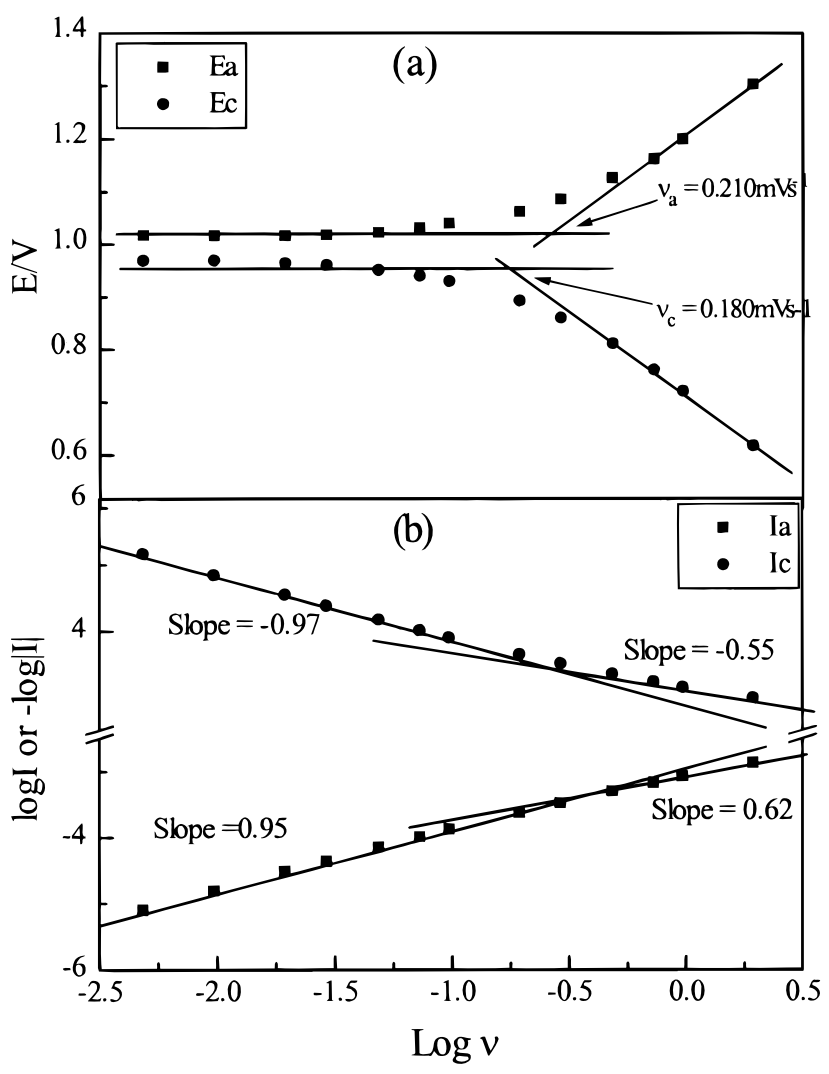

Figure 7. Dynamic studies of the poly[Ni(saltMe)]-modified electrode of Figure $5, \Gamma=1.1 \times 10^{-7} \mathrm{~mol} \mathrm{~cm}^{-2}$ : (a) plot of $E_{\mathrm{a}}$ and $E_{\mathrm{c}} \mathrm{vs} \log v$; (b) plot of $\log I_{\mathrm{a}}$ and $I_{\mathrm{c}}$ vs $\log v ; v_{\mathrm{a}}$ and $\nu_{\mathrm{c}}$ are, respectively, anodic and cathodic critical scan rates.

prepared with five $\left(\Gamma=0.96 \times 10^{-8} \mathrm{~mol} \mathrm{~cm}^{-2}\right)$ and 50 polymerization scans $\left(\Gamma=11.03 \times 10^{-8} \mathrm{~mol} \mathrm{~cm}^{-2}\right)$, for scan rates in the range $0.005-2.0 \mathrm{~V} \mathrm{~s}^{-1}$. Two different types of behavior are observed for peak potential and peak current as a function of scan rate. For the thin film and for all scan rates, as can be seen from Figures 4 and $6, E_{\mathrm{pa}} \approx E_{\mathrm{pc}}$, the waves are symmetrically shaped irrespective of $v$, and a linear dependence of anodic and cathodic peak current on the scan rate is observed. Thin layer/surface-type behavior is thus exhibited by the thin film. ${ }^{13}$

The thicker film shows, for slow scan rates, voltammetric waves with characteristics similar to those described for the thin film. With increasing $v$, the voltammograms start to resemble qualitatively those of solution reactants diffusing to the electrode (current-potential responses show tailing and $\Delta E$ becomes $>0.050 \mathrm{~V}$ ), for which semi-infinite diffusion predicts a linear relationship between $i_{\mathrm{p}}$ and $v^{1 / 2}$.

Plots of $E$ vs $\log v$ and of $\log i$ vs $\log v$ for the thicker film (Figure 7) reveal that there is a critical scan rate, $0.21 \mathrm{~V} \mathrm{~s}^{-1}$ for the anodic and $0.18 \mathrm{~V} \mathrm{~s}^{-1}$ for the cathodic process, for which $\Delta E$ starts to increase and the slope of $\log i$ vs $\log v$ decreases from 1 to approximately 0.5 . Both results indicate a change from a thin layer regime (where the peak current increases linearly with $v$ ) to semi-infinite diffusion control (where the peak current increases with $v^{1 / 2}$ ) for the thicker poly[Ni(saltMe)] film. This transition between the two regimes has been observed for other polymer-modified electrodes ${ }^{18,19}$ and, as suggested by Bartlett, ${ }^{20}$ is determined by the interplay between sweep rate and kinetics of charge transport throughout the film.

Under semi-infinite diffusion conditions, the peak current for a reversible electrode reaction is given by the Randles-Sevcik equation, ${ }^{21}$ which can be used to estimate the charge transport
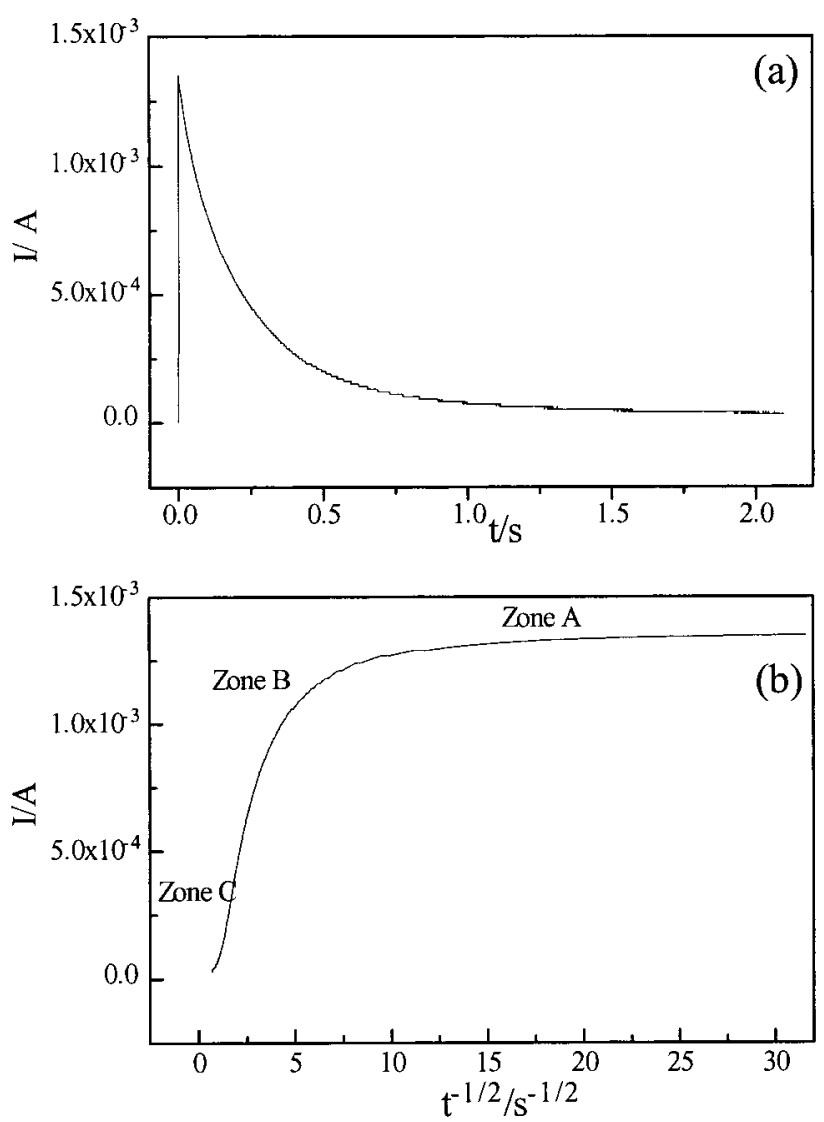

Figure 8. Typical chronoamperometric response of a poly[Ni(saltMe)]modified electrode, $\Gamma=1.1 \times 10^{-7} \mathrm{~mol} \mathrm{~cm}^{-2}$, for a 0.0 to $1.1 \mathrm{~V}$ potential step: (a) $i$ vs $t$; (b) $i$ vs $t^{-1 / 2}$ plot.

diffusion coefficient, $D_{\mathrm{CT}}(\mathrm{CV})$. For the work reported here, and for conditions where semi-infinite diffusion behavior is observed (scan rates in the range $0.75-2.0 \mathrm{~V} \mathrm{~s}^{-1}$ for the anodic reaction and $0.50-2.0 \mathrm{~V} \mathrm{~s}^{-1}$ for the cathodic reaction), the product $D_{\mathrm{CT}}^{1 / 2}$ (CV) $C$ was estimated from the plots of $i_{\mathrm{pa}}$ and $i_{\mathrm{pc}}$ vs $v^{1 / 2}$ and were found to be, respectively, $1.28 \times 10^{-7}$ and $1.05 \times 10^{-7}$ $\mathrm{mol} \mathrm{s}{ }^{-1 / 2} \mathrm{~cm}^{-2}$. These values compare well with those obtained by chronoamperometry (see below) and are in the range observed for other modified electrodes. ${ }^{22-24}$

Chronoamperometry Experiments. A series of potential step chronoamperometry experiments with films of several thicknesses were performed to assess the charge diffusion behavior of these new polymers. Figure 8 depicts typical chronoamperometric responses, $i$ vs $t$ plot and the resulting $i$ vs $t^{-1 / 2}$ representation.

The latter representation, based on the Cottrell equation for a semi-infinite diffusion system, deviates from the predicted straight line. We divide the curve into three zones. At very short times, zone $A$, the current intensity is significantly smaller than expected theoretically; this has been attributed to uncompensated resistance effects. ${ }^{25}$ Zone $B$, which is associated with intermediate times, corresponds to the diffusion-controlled regime. Paulse et al. ${ }^{26}$ assume that the Cottrell equation (semiinfinite diffusion system) pertains to the central portion of the $i$ vs $t^{-1 / 2}$ plot, and the most reasonable slope to adopt for data analysis is the tangent to the curve from the origin. In this way, we can extract values for $D_{\mathrm{CT}}^{1 / 2}(\mathrm{CA}) C$, where $D_{\mathrm{CT}}(\mathrm{CA})$ is the diffusion coefficient and $C$ is the concentration of the electroactive species. Finally, in zone $C$ (long times) the current intensity falls below the Cottrell line; this is because the polymer volume is not infinite, so a finite diffusion boundary condition must be invoked. We address this issue later in the paper. 
TABLE 1: Values of $D^{1 / 2} C$ Obtained from Chronoamperometry Using Cottrel Equation, for Polymers Obtained with a Different Number of Scans

\begin{tabular}{|c|c|c|c|c|c|c|c|}
\hline \multirow[b]{2}{*}{ no. of scans } & \multirow[b]{2}{*}{$10^{8} \Gamma\left(\mathrm{mol} \mathrm{cm}^{-2}\right)$} & \multicolumn{6}{|c|}{$10^{8} D^{1 / 2} C\left(\mathrm{~A} \cdot \mathrm{s}^{-1 / 2}\right)$} \\
\hline & & $0 \rightarrow 0.8 \mathrm{~V}$ & $0.8 \rightarrow 0 \mathrm{~V}$ & $0 \rightarrow 1.1 \mathrm{~V}$ & $1.1 \rightarrow 0 \mathrm{~V}$ & $0.8 \rightarrow 1.1 \mathrm{~V}$ & $1.1 \rightarrow 0.8 \mathrm{~V}$ \\
\hline 3 & 0.45 & 0.35 & 8.19 & 1.75 & 16.96 & 4.68 & 4.68 \\
\hline 5 & 0.96 & 1.17 & 11.70 & 4.68 & 26.31 & 7.02 & 7.02 \\
\hline 10 & 2.84 & 2.34 & 13.45 & 8.19 & 33.92 & 9.36 & 9.36 \\
\hline 20 & 2.80 & 2.34 & 12.28 & 8.19 & 33.33 & 9.36 & 9.36 \\
\hline 30 & 5.08 & 2.92 & 12.86 & 11.11 & 39.76 & 11.11 & 11.70 \\
\hline 40 & 8.51 & 3.51 & 11.70 & 12.86 & 42.69 & 12.28 & 12.86 \\
\hline 50 & 11.03 & 3.51 & 10.53 & 14.62 & 46.20 & 13.45 & 11.11 \\
\hline
\end{tabular}

In Table 1 are included the values of $D_{\mathrm{CT}}^{1 / 2}(\mathrm{CA}) C$ for poly$[\mathrm{Ni}(\mathrm{saltMe})]$ films with different thickness for three different potential steps. For each film thickness, the values of the product $D_{\mathrm{CT}}^{1 / 2}(\mathrm{CA}) C$ for oxidation are lower than the corresponding reduction, the exception is for small potential steps $(0.8 \rightarrow 1.1 \mathrm{~V}$ and the reverse step) in multi-potential-step experiments, for which $D_{\mathrm{CT}}^{1 / 2}(\mathrm{CA}) C_{\text {anod }} \approx D_{\mathrm{CT}}^{1 / 2}(\mathrm{CA}) C_{\text {cath }}$. From these results we draw two conclusions regarding charge propagation within the polymer.

First, as the initial concentration of the active sites in the film for the oxidative potential step $\left(C_{\text {anod }}\right)$ is greater than the initial concentration of the oxidized sites in the swollen film $\left(C_{\text {cath }}\right)$ for the reduction step (see below), our data indicate that $D_{\mathrm{CT}}(\mathrm{CA})_{\text {anod }}$ following large potential steps is smaller than $D_{\mathrm{CT}}$ (CA) cath. A possible explanation for this result is that polymers in their neutral state (low doping level) are expected to have a more compact structure than polymers in their oxidized state, as film oxidation involves ingress of ions and solvent swelling. This process imposes an increase in fluidity of the polymeric matrix that will impart in the reverse process more freedom to the species required to exit from the polymer; this eases reduction.

Second, we note that (i) in oxidative and reductive experiments with multiple potential steps the $D_{\mathrm{CT}}^{1 / 2}(\mathrm{CA}) C$ values are very similar for the intermediate steps $0.8 \rightarrow 1.1 \mathrm{~V}$ and $1.1 \rightarrow$ $0.8 \mathrm{~V}$; (ii) the values of $D_{\mathrm{CT}}^{1 / 2}(\mathrm{CA}) C$ for $0.0 \rightarrow 0.8 \mathrm{~V}$ steps are smaller than those for $0.8 \rightarrow 1.1 \mathrm{~V}$ steps; and (iii) the values of $D_{\mathrm{CT}}^{1 / 2}(\mathrm{CA}) C$ for $0.8 \rightarrow 0.0 \mathrm{~V}$ steps are larger than those for 1.1 $\rightarrow 0.8 \mathrm{~V}$ steps. Coupling these observations with the explanation above, we propose that ingress of ions and polymer swelling take place predominantly up to $0.8 \mathrm{~V}$ during film oxidation.

Direct analysis of $D_{\mathrm{CT}}(\mathrm{CA})$ as a function of the film thickness (measured as $\Gamma$ ) cannot be done as only the product $D_{\mathrm{CT}}^{1 / 2}(\mathrm{CA})$ $C$ is available by the present study. The absolute values of the product $D_{\mathrm{CT}}^{1 / 2}(\mathrm{CA}) C$ increase with thickness, although in a nonlinear fashion: thin films show the greater increases, whereas the values of $D_{\mathrm{CT}}^{1 / 2}(\mathrm{CA}) C$ reach a plateau for the thicker films.

With respect to zone $C$, we were also interested to confirm the idea that deviations from the predicted values for semiinfinite Cottrell behavior were due to the finite boundary condition. For a potential step experiment with a reactant solution of thickness $d$, the finite diffusion current-time dependence is described by ${ }^{24,27}$

$$
\begin{aligned}
i=\frac{n F A D^{1 / 2} C}{\pi^{1 / 2} t^{1 / 2}}\left\{\sum _ { \infty } ^ { k = 0 } ( - 1 ) ^ { k } \left[\exp \left(\frac{-k^{2} d^{2}}{D t}\right)-\right.\right. \\
\left.\left.\exp \left(\frac{-(k+1)^{2} d^{2}}{D t}\right)\right]\right\}
\end{aligned}
$$

where $A$ is the area of the electrode, $D$ is taken to be $D_{\mathrm{CT}}(\mathrm{CA})$ (charge transport diffusion coefficient determined by chronoamperometry), $C$ is the concentration of the redox species, $d$ is

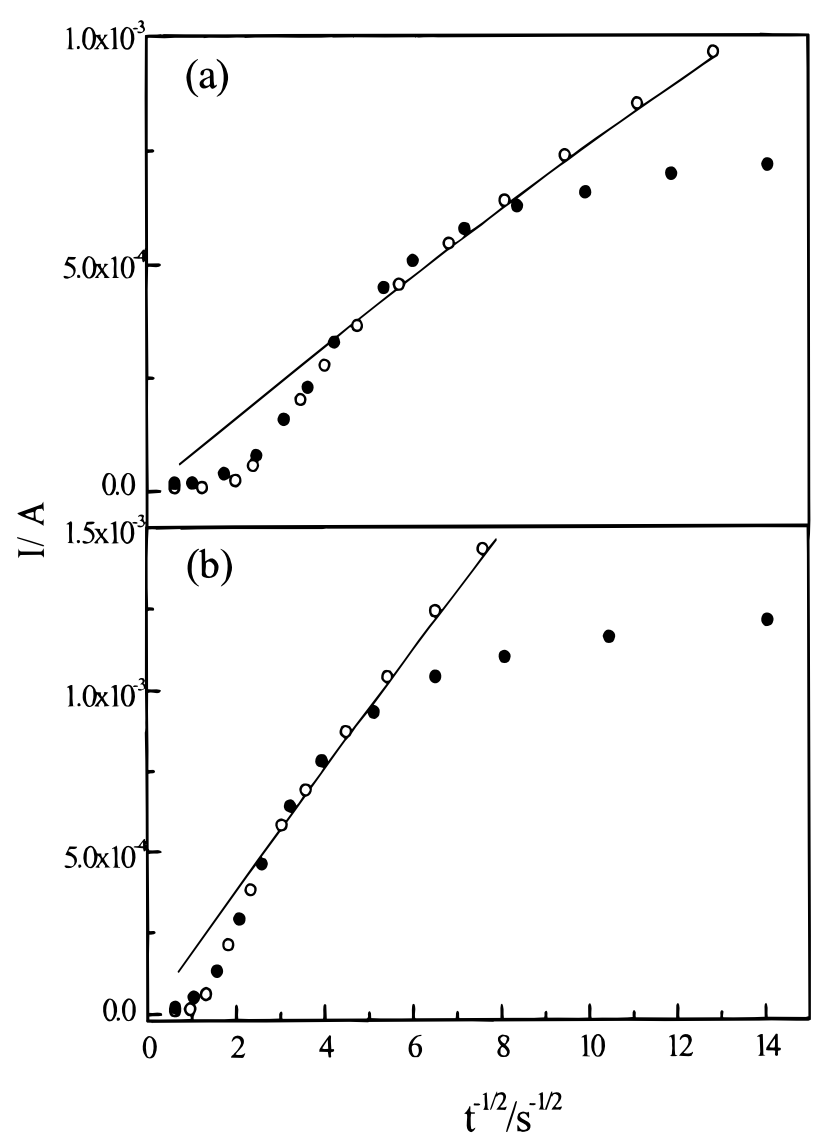

Figure 9. $i$ vs $t^{-1 / 2}$ plot for a $0.0-1.1 \mathrm{~V}$ potential step: experimental data (@), Cottrell equation (-), and eq 1 (O). (a) $\Gamma=9.6 \times 10^{-9} \mathrm{~mol}$ $\mathrm{cm}^{-2}$; (b) $\Gamma=1.1 \times 10^{-7} \mathrm{~mol} \mathrm{~cm}^{-2}$.

the thickness of the film, and $n, F$, and $t$ have their usual meanings. To fit eq 1 to the experimental data requires knowledge of the ratio $d^{2} / D$. From $C=(\Gamma / d)$ it follows that $d^{2} / D=\left(\Gamma / D^{1 / 2} C\right)^{2}$, and using for $D^{1 / 2} C$ the $D_{\mathrm{CT}}^{1 / 2}(\mathrm{CA}) C$ values obtained from the slope of the tangent to the $i$ vs $t^{-1 / 2}$ curve from the origin, and the electroactive surface coverage, it is possible to estimate $d^{2} / D$.

Experimental $i$ vs $t^{-1 / 2}$ curves and chronoamperometric current-time responses predicted by the Cottrell equation and by eq 1 , for a thin $\left(\Gamma=0.96 \times 10^{-8} \mathrm{~mol} \mathrm{~cm}^{-2}\right)$ and for a thick film $\left(\Gamma=11.03 \times 10^{-8} \mathrm{~mol} \mathrm{~cm}{ }^{-2}\right)$, are shown in Figure 9, panels a and $b$, respectively. The calculated diffusional response from eq 1 is in very good agreement with the experimental data, except for very short times, where the current intensity is controlled by the solution resistance. This agreement clearly indicates that in these experiments a changeover occurs, from a semi-infinite diffusion condition described by the Cottrell equation to a finite diffusion regime, with time following the potential step. In the context of the above discussion, it is predicted that the changeover between the two regimes occurs at different times for polymers of different thickness: the switch 

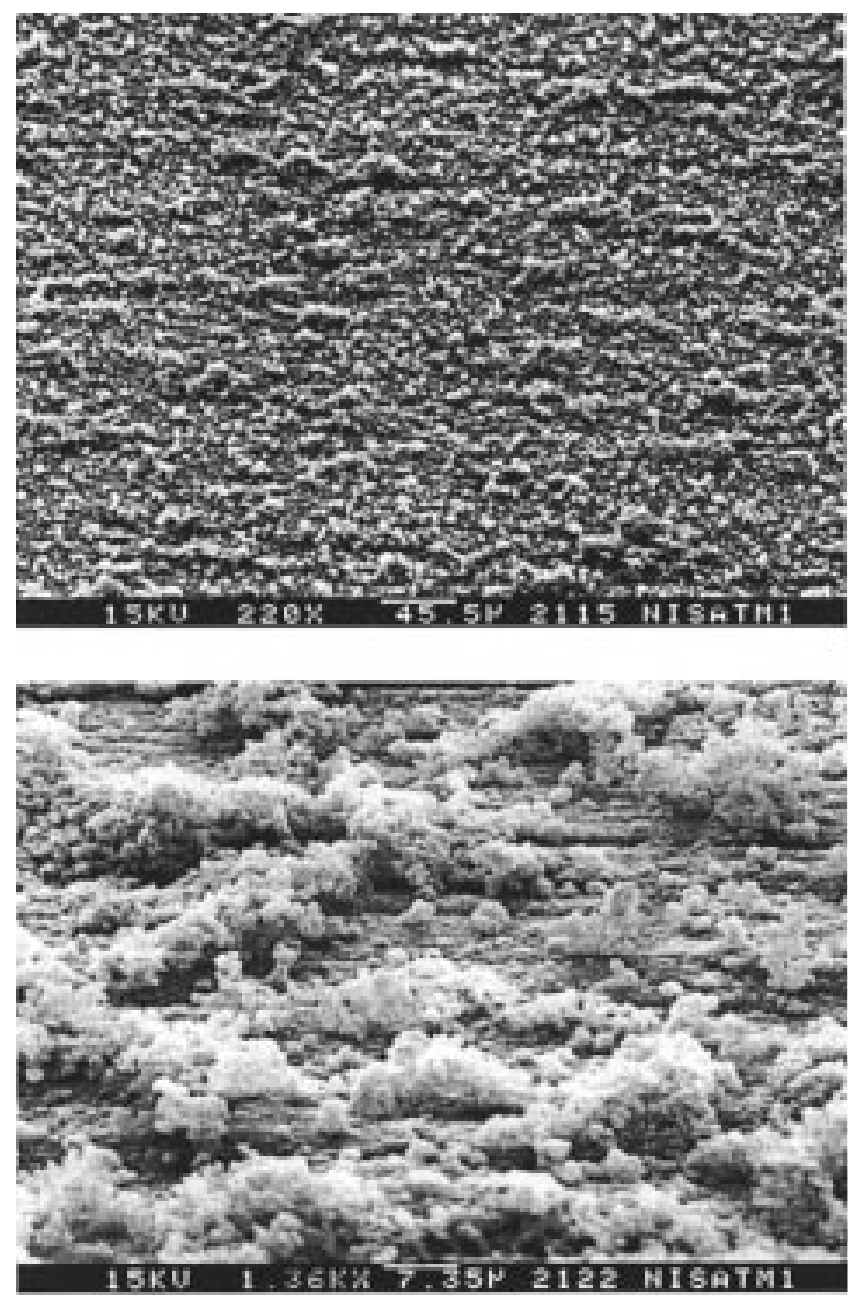

Figure 10. Scanning electron micrographs of a thick poly[Ni(saltMe)] film deposited on a Pt foil.

will be at longer times for thicker films. Comparison of panels $\mathrm{a}$ and $\mathrm{b}$ of Figure 9 reveals exactly this.

Scanning Electron Microscopy. In Figure 10 (top) we present a typical scanning electron micrograph of a poly[Ni(saltMe)] film deposited onto a Pt foil electrode. The polymer looks compact and shows a continuous morphology over the entire film. With higher resolution, Figure 10 (bottom), it is possible to see that the film consists of a continuous layer, on top of which there are irregular patches with granular shape. From the X-ray analysis we observe that the ratio Ni/Pt is lower on the layer than on the patches, which is indicative that the polymer grows outward from the continuous layer.

SEM experiments with the polymer in the neutral and in the oxidized state show that film morphology does not seem to depend on the oxidation state of the polymer and that the concentration of $\mathrm{ClO}_{4}{ }^{-}$is higher in the oxidized than in the neutral film, indicating that ingress of $\mathrm{ClO}_{4}{ }^{-}$occurs on oxidation of the polymer to maintain charge compensation.

\section{Conclusions}

By using the monomer [Ni(saltMe)], which structurally differs from $[\mathrm{Ni}($ salen)] by the four methyl groups in the ethylenimine bridge, we were able to electrogenerate by oxidative polymerization polymer films that exhibit reversible oxidative electrochemical behavior in a wide potential range $(0-1.3 \mathrm{~V})$, high conductivity, and stability/durability in $\mathrm{CH}_{3} \mathrm{CN} / 0.1 \mathrm{~mol} \mathrm{dm}{ }^{-3}$ TEAP. These properties allowed, for the first time, the study of the kinetics of charge propagation within a polymer film based on a $\mathrm{Ni}$ (II) complex with a Schiff base derived from salicylaldehyde.

We have found that films of poly[Ni(saltMe)] can be made to exhibit the three regimes of charge transport behavior by manipulation of the film thickness and the experimental time scale. On long time scales (cyclic voltammetry) and for films prepared by a small/intermediate number of potential cycles $(1$ to $\approx 30, \Gamma$ in the range $0.40 \times 10^{-8}$ to $5.08 \times 10^{-8} \mathrm{~mol} \mathrm{~cm}^{-2}$ ) thin-layer/surface-type behavior prevails for all accessible scan rates. For thicker polymers (number of potential cycles greater than $40, \Gamma>8.51 \times 10^{-8} \mathrm{~mol} \mathrm{~cm}{ }^{-2}$ ) a changeover from the thin-layer regime at low scan rates to a diffusion-controlled regime at high scan rates is observed at a critical scan rate that is dependent on film thickness. The short time scale potential step method (chronoamperometry) has provided valuable information on diffusive charge transport within the polymer: in these experiments a transition from the semi-infinite diffusion condition (shorter times) to the finite diffusion condition (longer times) is also observed, with time following the potential step.

Cyclic voltammetric and chronoamperometric data allowed estimation of the product $D_{\mathrm{CT}}^{1 / 2} C$ for the second electrochemical process in the oxidative redox switching. The values obtained from the two techniques for films of the same thickness were in good agreement. Moreover, the comparison of the $D_{\mathrm{CT}}^{1 / 2} C$ values for the oxidative and reductive electrochemical reactions, as well as their dependence on film thickness, was interpreted to suggest that ingress of counterions and solvent swelling may occur predominantly up to $0.8 \mathrm{~V}$ in the positive-going scan.

Finally, the degree of oxidation of poly[Ni(saltMe)] for the positive potential limit employed was estimated to be approximately one electron per monomer unit. On the basis of electrochemical data the surface redox couple could not be identified unambiguously; this will be the subject of a subsequent spectroelectrochemical study.

Acknowledgment. This work was partially supported by the Fundação para a Ciência e Tecnologia through Project PBIC/ QUI/2137/95. M.V.-B. thanks the FCT/Praxis XXI for a fellowship. Isabel Santos performed some coulometric and surface coverage experiments.

\section{References and Notes}

(1) Gosden, C.; Hely, K. P.; Pletcher, D. J. Chem. Soc., Dalton Trans. 1978, 972

(2) Healy, K. P.; Pletcher, D. J. J. Organomet. Chem. 1980, 186, 401

(3) Gosden, C.; Kerr, J. B.; Pletcher, D. J.; Rosas, R. J. Electroanal. Chem. Interfacial Electrochem. 1981, 117, 101.

(4) Goldsby, K. A. J. Coord. Chem. 1988, 19, 83.

(5) Goldsby, K. A.; Hoferkamp, L. A. Chem. Mater. 1989, 1, 348.

(6) Audbert, P.; Hapiot, P.; Capdevielle, P.; Maumy, M. J. Electroanal. Chem. Interfacial Electrochem. 1992, 338, 269.

(7) Audebert, P.; Capdevielle, P.; Maumy, M. New J. Chem. 1992 16,697

(8) Maumy, M.; Capdevielle, P.; Aubert, P. H.; Audebert, P.; Roche, M. New J. Chem. 1997, 21, 621.

(9) Bedioui, F.; Labbe, E.; Gutierrez-Granados, S.; Devynck, J. J. Electroanal. Chem. Interfacial Electrochem. 1991, 301, 267.

(10) Dahm, C. E.; Peters, D. G.; Simonet, J. J. Electroanal. Chem. 1996, $410,163$.

(11) Vilas-Boas, M.; Freire, C.; Castro, B.; Hillman, A. R.; Christensen, P. A. Inorg. Chem. 1997, 36, 4919.

(12) Dahm, C. E.; Peters, D. G. J. Electroanal. Chem. Interfacial Electrochem. 1996, 406, 119.

(13) Kelly, D. M.; Vos, J. G Electroactive Polymer Electrochemistry Part 1: Fundamentals; Lyons, M. E. G., Ed.; Plenum Press: New York, 1994; Chapter 8.

(14) Freire, C.; Castro, B.; J. Chem. Soc., Dalton. Trans. 1998, 1491.

(15) Bedioui, F.; Merino, A.; Devynck, J.; Mestres, C.; Bied-Charreton, C. J. Electroanal. Chem. 1988, 239, 433. 
(16) Armengaud, C.; Moisy, P.; Bedioui, F.; Devynck, J.; BiedCharreton, C. J. Electroanal. Chem. 1990, 277, 197.

(17) Daire, F.; Bedioui, F.; Devynck, J.; Bied-Charreton, C. J. Electroanal. Chem. 1987, 224, 95.

(18) Bedioui, F.; Voisin, M.; Devynck; J.; Bied-Charreton, C. J. Electroanal. Chem. 1991, 297, 257.

(19) Martin, C. R.; Rubinstein, I.; Bard, A. J. J. Am. Chem. Soc. 1982, 104, 4817.

(20) Bartlett, P. N. Biosensors: Fundamentals and Applications; Turner, A. P. F.; Karube, I.; Wilson, G. S., Eds.; Oxford University Press: Oxford, England; 1987, Chapter 13
(21) Sevcik, A. Collect. Czech. Chem. Commun. 1948, 20, 327.

(22) Daum, P.; Murray, R. J. Phys. Chem. 1981, 85, 389.

(23) Daum, P.; Lenhard, J. R.; Rolison, D.; Murray, R. J. Am. Chem. Soc. 1980, 102, 4649 .

(24) Oyama, N.; Ohsaka, T. Molecular Design of Electrode Surface; Murray, R. W., Ed; Wiley: New York, 1992; Chapter VIII.

(25) Lyons, M. E. G. Electroactive Polymer Electrochemistry Part 1: Fundamentals; Lyons, M. E. G., Ed.; Plenum Press: New York, 1994; Chapter 1 .

(26) Paulse, C. D.; Pickup, P. G. J. Phys. Chem. 1988, 92, 7002.

(27) Lane, R. F.; Hubbard, A. T. J. Phys. Chem. 1973, 77, 1401. 